\title{
Assessment of Agreement between Gates Method and Dual Plasma Sample Method for Measurement of Glomerular Filtration Rate
}

\author{
${ }^{1}$ Pupree Mutsuddy, ${ }^{1}$ Mohammad Anwar-Ul- Azim, ${ }^{1}$ Shamim M F Begum, ${ }^{1}$ Raihan Hussain, ${ }^{1}$ Sharmin Farhana, ${ }^{1}$ Taslima Sifat, \\ $\mathbf{2}_{\text {Samira Sharmin and }}{ }^{3}$ Afroza Naznin

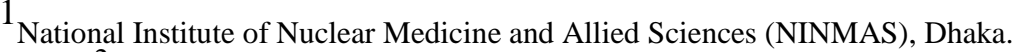 \\ 2 Institute of Nuclear Medicine and Allied Sciences (INMAS), Mitford, Dhaka. \\ 3 Institute of Nuclear Medicine and Allied Sciences (INMAS), Sylhet.
}

Correspondence Address : Dr. Pupree Mutsuddy, Senior Medical Officer, National Institute of Nuclear Medicine \& Allied Sciences (NINMAS), Dhaka, Bangladesh, Email: pupreesomc40@ gmail.com

\begin{abstract}
Objectives: Glomerular filtration rate (GFR) is generally considered to be the best index of renal function in both healthy and diseased kidneys. Calculation of GFR plays a vital role in the management of patients having renal diseases. Clinicians can make their final decision regarding the potential need for kidney transplantation and also selection of a potential kidney donor. Many methods have been developed in order to obtain more accurate GFR values. The most popular radionuclide method is camera based Gates method using ${ }^{99 m}$ Tc DTPA (Diethylene triaminepentaacetic acid). This method can provide immediate calculation of individual kidney function as well as of global renal function. But several sources of errors may reduce the reliability of this method. Measurement of multiple blood samples offers almost real values of GFR, which have become the gold standard in clinical research. The aim of this research work was to study the agreement between Gates method and dual plasma sample method for measurement of GFR.

Patients and methods: This cross sectional study was carried out in National Institute of Nuclear Medicine \& Allied Sciences (NINMAS), during July 2015 to June 2016. A total of 59 patients were included in this study. GFR was estimated by both the camera based Gates method and dual plasma sample method (DPSM).Statistical analyses were carried out by using the Statistical Package for Social Sciences version 20.0 for Windows (SPSS Inc., Chicago, Illinois, USA). The mean values were calculated for continuous variables. Categorical data were expressed in percentage and number. Pearson correlation and Bland \& Altman (B \& A) analyses were applied for assessing correlation and agreement between Gates method and DPSM. Degree of relation between the variables is expressed by $r$ (Pearson's correlation coefficient).
\end{abstract}

Results: The mean GFR evaluated by Gates method was found $82.2 \pm$ $27.4 \mathrm{~mL} / \mathrm{min} / 1.73 \mathrm{~m}^{2}$ and mean GFR by DPSM was found $82.8 \pm 24.1$ $\mathrm{mL} / \mathrm{min} / 1.73 \mathrm{~m}^{2}$. A strong positive correlation $(r=0.833 ; p=0.001)$ was found between the GFR values measured by Gates method and DPSM. With Bland and Altman analysis, it was observed that mean difference of GFR measured by Gates method and DPSM was - $0.6 \pm 15.22$ $\mathrm{mL} / \mathrm{min} / 1.73 \mathrm{~m}^{2}$. The limit of agreement ranged from - 30.44 $\mathrm{mL} / \mathrm{min} / 1.73 \mathrm{~m}^{2}$ to $29.24 \mathrm{~mL} / \mathrm{min} / 1.73 \mathrm{~m}^{2}$.

Conclusion: There was strong positive correlation between Gates method and DPSM for measurement of GFR. Mean difference between the methods was small. The bias between the methods was considered not significant. The differences within mean \pm 1.96 SD are not clinically important. Hence Gates method and DPSM can reflect GFR almost equally and can be used interchangeably.

Key words: Glomerular filtration rate, Gates method, dual plasma sample method.

\section{INTRODUCTION}

Glomerular filtration rate (GFR) is an important indicator of the functional status of the kidney and is defined as the volume of fluid filtered from the renal glomerular capillaries into the Bowman's capsule per unit time (1). About $10 \%$ of the renal blood flow, which is around $20 \%$ of cardiac output at rest (1-1.2 L/min), is filtered and make up the primary urine. The filtration speed of the primary urine is the glomerular filtration rate and is approximately 120 $\mathrm{mL} / \mathrm{min}$ (2). Increased hydrostatic pressure in the glomerular capillaries increases GFR. On the other hand increased hydrostatic pressure in the Bowman's capsule and increased colloidal osmotic pressure in the glomerular capillaries decrease GFR.

Many methods have been developed in order to obtain more accurate value and simpler procedure for GFR measurement. The commonly used methods are estimated GFR or eGFR, serum cystatin C, camera renogram (Gates method), plasma sampling method and twenty four hours endogenous creatinine clearance. The "gold standard" for GFR estimation 
has been considered to be that of continuous infusion of inulin with urine and plasma sampling; but this method is technically difficult and is rarely performed in a clinical setting (3).

Measurement of GFR, using a radiation emitting agent, is practical as measuring radioactivity is simple and more accurate. ${ }^{51} \mathrm{Cr}$ EDTA and ${ }^{125} \mathrm{I}$ iothalamate were frequently used for true GFR measurement, but these agents were expensive, the technique were time consuming and highly dependent on the accuracy of urine collection $(4,5)$. On the other hand, ${ }^{99 \mathrm{~m} T c}$ DTPA is relatively cheaper and readily available agent, which is completely filtered by glomeruli and not secreted or reabsorbed by renal tubuli (6). Camera-based noninvasive scintigraphic method to evaluate GFR is comparable to standard methods of GFR determination (e.g., inulin clearance and creatinine clearance) $(7,8)$.

Measurement of multiple blood samples offers almost real values of GFR, which have become the gold standard in clinical research. Their simplification has been achieved by reduction of the number of blood samples to two or even one (9). DPSM using Russell's formula vouched as a reliable method for the valid estimate of true GFR (10).GFR is useful in early detection of renal impairment, for monitoring renal function and also provides guidance in the dosing of naphrotoxic drugs. Moreover the classification of chronic renal disease is dependent on the accurate calculation of GFR (3). Hence it is worthy to establish a procedure for the valid estimation of GFR in routine Nuclear Medicine procedure.

\section{PATIENTS AND METHODS}

A total of 59 patients attended in NINMAS at Bangabandhu Sheikh Mujib Medical University (BSMMU) campus, during July 2015 and June 2016, were included in this study. Patients underwent nuclear medicine imaging for ${ }^{99 \mathrm{~m}} \mathrm{Tc}$ DTPA renogram along with GFR estimation were enrolled in this study. Patients under 18 years of age, severely ill patient, pregnant and lactating mother were excluded. The respondents were briefed about the details of the study procedure and radioisotopes were administered maintaining internationally recommended safe procedures.

Good hydration and voiding were maintained prior to the beginning of study. Approximately $111 \mathrm{MBq}$ to $185 \mathrm{MBq}$ (3 to $5 \mathrm{mCi}$ ) of ${ }^{99 \mathrm{~m} T c}$ DTPA in equal volume were prepared in two syringes, marked as standard and patient dose.

Routine dynamic renal scan was performed after intravenous injection of patient dose. After scintigraphy, the site of injection on the arm was scanned under the gamma camera. The residual radioactivity at the injection site was less than $0.1 \%$ in all subjects.

GFR for each of the patient was measured by modified Gates algorithm automatically by the computer available software (11).

Blood was drawn at 60th and 180th minute post injection from the contra lateral arm and centrifuged at room temperature for 5 minutes. The standard dose was prepared by diluting in normal saline $(0.9 \% \mathrm{NaCl})$. Equal aliquots of plasma and standard were counted in single well gamma well counter for 1 minute.

GFR was calculated by using the Russell's equation

$$
\text { (9): }\left[\frac{\mathrm{Q} \ln \left(\mathrm{P}_{1} / \mathrm{P}_{2}\right)}{\mathrm{T}_{2}-\mathrm{T}_{1}} \exp \frac{\mathrm{T}_{1} \ln \mathrm{P}_{2}-\mathrm{T}_{2} \ln \mathrm{P}_{1}}{\mathrm{~T}_{2}-\mathrm{T}_{1}}\right]
$$

Where, $\mathrm{Q}=$ total injected dose counts $(\mathrm{cpm}), \mathrm{P} 1=$ activity $(\mathrm{cpm} / \mathrm{mL})$ at the time of $\mathrm{T} 1, \mathrm{P} 2=$ activity $(\mathrm{cpm} / \mathrm{mL})$ at the time of $\mathrm{T} 2, \mathrm{~T} 1=60 \mathrm{~min}$ and $\mathrm{T} 2=180 \mathrm{~min}$.

GFR was corrected to the standard BSA using the equation (12):

\section{GFRCorr $=$ GFR $\times(1.73 /$ BSA m2 $)$}

Values of BSA were estimated from the height and weight using the Haycock's formula (13): BSA $\left(\mathrm{m}^{2}\right)$ $=0.024265 \times \mathrm{Wt}^{0.5378} \times \mathrm{Ht}^{0.3964}$ 
Two different GFR values obtained by Gates method and Russell's DPSM were analyzed to assess the agreement and comparison between the GFR values.

Quality control of all used equipments (gamma camera, dose calibrator, well counter etc.) was performed routinely. The radiochemical purity of ${ }^{99 \mathrm{~m}}$ Tc DTPA was maintained $>95 \%$.

\section{RESULTS}

The study included 59 patients (32 males, 27 females) with mean age $37.9 \pm 13.7$ years (range, 18-80 years), mean height $157.8 \pm 8.4 \mathrm{~cm}$ and mean weight $59.2 \pm 9.4 \mathrm{~kg}$.

The most common clinical diagnosis was unilateral hydronephrosis (right sided hydronephrosis: $37.3 \%$ and left sided hydronephrosis $35.6 \%$ ) and $72.9 \%$ of the patients had serum creatinine level higher than the reference range.

In the present study among 59 patients, more than half $(52.5 \%)$ patients had GFR level $<90$ $\mathrm{mL} / \mathrm{min} / 1.73 \mathrm{~m} 2$ and mean GFR value was found $82.2 \pm 27.4 \mathrm{~mL} / \mathrm{min} / 1.73 \mathrm{~m} 2$ evaluated by Gates method (Table 1). On the other hand, 59.3\% of the total patients had GFR level $<90 \mathrm{~mL} / \mathrm{min} / 1.73 \mathrm{~m} 2$ and the mean GFR value was found $82.8 \pm 24.1$ $\mathrm{mL} / \mathrm{min} / 1.73 \mathrm{~m} 2$ evaluated by DPSM (Table 2 ).

There was a significant strong positive correlation between the GFR level measured by Gates method and DPSM (Figure 1). Bland-Altman plot for Gates method and DPSM for GFR measurement shows the mean difference of GFR measured by Gates method and DPSM was $-0.6 \pm 15.22 \mathrm{~mL} / \mathrm{min} / 1.73 \mathrm{~m} 2.95 \%$ of differences were found in between - 30.44 $\mathrm{mL} / \mathrm{min} / 1.73 \mathrm{~m} 2$ and $29.24 \mathrm{~mL} / \mathrm{min} / 1.73 \mathrm{~m} 2$ (Figure 2).

Table 1: GFR distribution of the studied patients evaluated by Gates method $(n=59)$

\begin{tabular}{ccccc}
\hline $\begin{array}{c}\text { Gates GFR } \\
\left(\mathrm{mL} / \mathrm{min} / 1.7 \mathrm{~m}^{2}\right)\end{array}$ & Number of patients & Percentage Mean \pm SD (min, max) \\
\hline$<90$ & 31 & 52.5 & \\
$90-120$ & 23 & 39.0 & $82.2 \pm 27.4$ & $29.3,129.7$ \\
$>120$ & 5 & 8.5 & \\
\hline
\end{tabular}

Table 2: GFR distribution of the studied patients evaluated by DPSM $(n=59)$

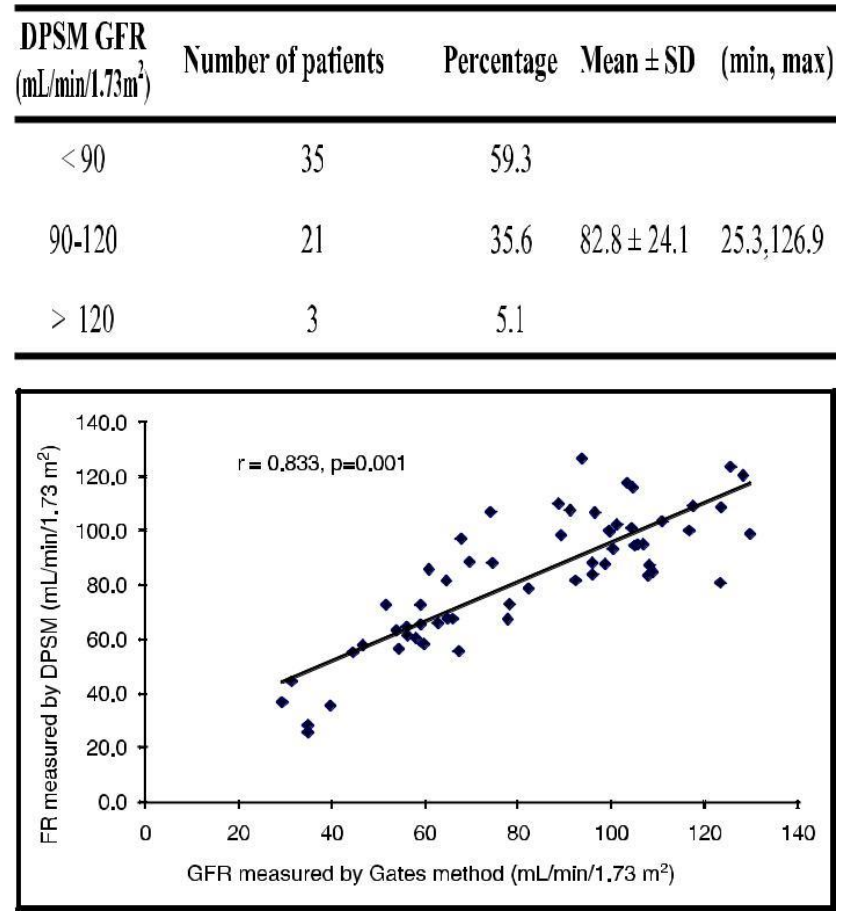

Figure 1: Scatter diagram showing positive correlation $(r=0.833 ; p=0.001)$ between the GFR measured by Gates method and DPSM.

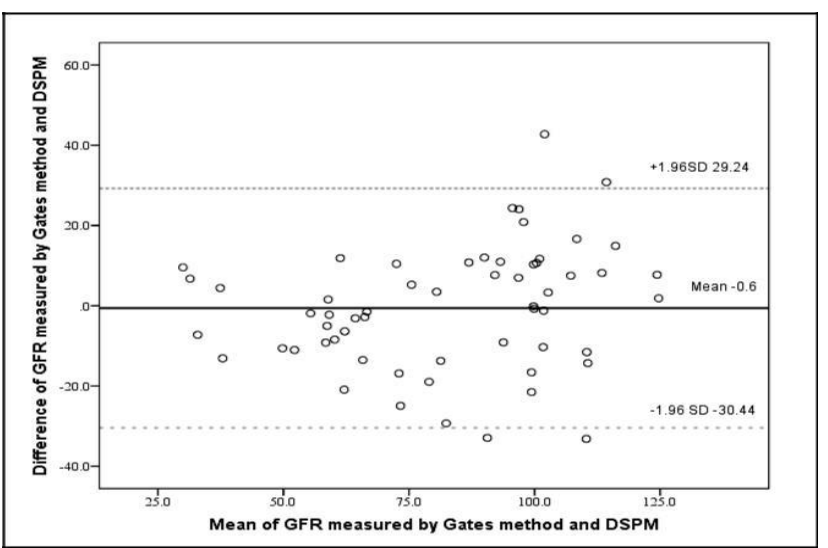

Figure 2: Scatter diagram showing agreement between the GFR measured by Gates method and DPSM

\section{DISCUSSION}

In this current study it was observed that more than one third $(39.0 \%)$ patients belonged to age $\leq 30$ years and the mean age was found $37.9 \pm 13.7$ years. Muammaer et al. found the median age was 34 years with range from 20 to 52 years, which is comparable with the current study (6). Younis et al. and Ayan et al. observed 
similar age ranged from 25 to 70 years and 22 to 65 years respectively $(14,15)$.

In this present study more than half $(54.2 \%)$ of the patients were male and $45.8 \%$ patients were female. Aydin et al. found 59 males and 25 females in their study (16). Similarly, male predominant also observed by Younis et al. and Itoh $(14,17)$.

Jackson et al. reported that the Gates method tended to overestimate GFR in comparison to the dual sample in vitro method (18). Itoh also reported overestimated GFR values with the Gates method and indicated that the overestimation might be attributable to insufficient correction for background activity in the kidney (17). In this study, in case of Gates method, it was observed that more than half (52.5\%) patients had GFR level of $<90 \mathrm{~mL} / \mathrm{min} / 1.73 \mathrm{~m} 2$ and the mean GFR was found $82.2 \pm 27.4 \mathrm{~mL} / \mathrm{min} / 1.73 \mathrm{~m} 2$ with ranged from 29.3 to $129.7 \mathrm{~mL} / \mathrm{min} / 1.73 \mathrm{~m} 2$. Younis et al. found GFR measurement) varied from 42.3 to $98 \mathrm{~mL} / \mathrm{min} / 1.73 \mathrm{~m} 2$ with mean value $74.1 \pm 14.5 \mathrm{~mL} / \mathrm{min} / 1.73 \mathrm{~m} 2$ by using Gates method (15). Similar findings also reported by Hephzibah et al. (3), which are comparable with the current study. On the other hand Ayan et al. found the mean GFR was $105.25 \pm 16.12 \mathrm{~mL} / \mathrm{min} / 1.73 \mathrm{~m} 2$, which is higher than the current study (15).

Zuo et al. reported that the DPSM should be used in order to obtain reliable reference GFR values, when GFR is less than $45 \mathrm{~mL} / \mathrm{min} / 1.73 \mathrm{~m} 2$ (19). In this study, almost two third (59.3\%) patients had GFR level $<90 \mathrm{~mL} / \mathrm{min} / 1.73 \mathrm{~m} 2$ and the mean GFR was found $82.8 \pm 24.1 \mathrm{~mL} / \mathrm{min} / 1.73 \mathrm{~m} 2$ with range from 25.3 to $126.9 \mathrm{~mL} / \mathrm{min} / 1.73 \mathrm{~m} 2$ measured by DPSM. Younis et al. found GFR by using DPSM with range from 39.2 to $139.6 \mathrm{~mL} / \mathrm{min} / 1.73 \mathrm{~m} 2$, which is comparable with the current study (14).

In this current study, a strong positive correlation $(\mathrm{r}=$ $0.833 ; p=0.001)$ was observed in between the GFRs values, measured Gates method and DPSM, which is closely resembled with several studies $(10,14,15)$.
In this present study it was observed that mean difference of GFR measured by Gates method and DPSM was small. Similar findings also observed by Ayan et al. (15).

\section{CONCLUSION}

In this study most of the patients had GFR values $<90$ $\mathrm{mL} / \mathrm{min} / 1.73 \mathrm{~m} 2$ evaluated by both the Gates method and DPSM. There is strong positive correlation between Gates method with DPSM. With Bland and Altman analysis mean difference between the methods was small. So, Gates method and DPSM can reflect GFR almost equally and can be used interchangeably.

\section{REFERENCES}

1. Prakash Dibya. A guide for Healthcare Professionals and patients. India: Springer; 2014 [Accessed 20 July 2016]. Available from: http://www.springer.com.

2. Dirk Manski.Urology-textbook.2015[Accessed 3 March 2016]. Available from: http:// www. urology-textbook.com/kidney glomerular filtration rate.

3. Hephzibah J, Shanthly N and Oommen R. Comparison of glomerular filtration rate measured by plasma sample technique, Cockroft Gault method and Gates method in voluntary kidney donors and renal transplant recipients. Indian J Nucl Med 2013;28(3):144-51.

4. Odlind B, Hallgren R, Sohtell $M$ and Lindstrom B. Is I-125 iothalamate an ideal marker for glomerular filtration?. Kidney International 1985;27(1):9-16.

5. Aparicio SA, Mojiminiyi S, Kay JD, Shepstone BJ, Ceulaer DK and Serjeant GR. Measurement of glomerular filtration rate in homozygous sickle cell disease: a comparison of Cr-51 EDTA clearance, creatinine clearance, serum creatinine and beta-2 microglobulin. J Clin Pathol 1990;43(5):370-2.

6. Muammer U, Ayse M, Muhammet SS, Ramazan CK and Yavuz NA. Comparison of Glomerular Filtration Rate Measurement Methods Using Technetium-99m Diethylenetriaminepentaacetic Acid. Turk J Nucl Med 2007;16:25-31.

7. Krawiec DR, Badertscher RR 2nd, Twardock AR, Rubin SI and Gelberg HB. Evaluation of technetium-99m-diethylene triaminepentaacetic-acid nuclear imaging for quantitative determination of the glomerular filtration rate of dogs. Am J Vet Res1986;47(10):2175-79.

8. Twardock AR, Krawiec DR and Itkin RJ: Renal imaging I and II: Functional renal scintigraphy, in: Berry CR and Daniel GB (eds): Handbook of Veterinary Nuclear Medicine. Raleigh, NC, North Carolina State University, pp122-32;1996.

9. Russell CD, Bischoff PG, Kontzen FN, Rowell KL, Yester MV, Lloyd LK et al. Measurement of glomerular filtration rate: single injection plasma clearance method without urine collection. J Nucl Med 1985;26:1243-7. 
10. Mulligan JS, Blue PW and Hasbargen JA. Methods for measuring GFR with technetium-99m-DTPA: An analysis of several common methods. J Nucl Med 1990;31(7):1211-9.

11. Beytas EM, Hamblen SM, Hanson MW and Thomas FD. GFR Determination by a Modification of the Gates Method: The Conventional Renal Examination with a Semi-Automated GFR Measurement. J Nucl Med Technol 1990;18:256-60.

12. Gates GF. Computation of glomerular filtration rate with Tc-99m DTPA: An in-house computer program. J Nucl Med 1984;25:613-8.

13. Haycock GB, Schwartz GJ, Wisotsky DH. Geometric method for measuring body surface area: A height-weight formula validated in infants, children, and adults. J Pediatr 1978;93:62-6.

14. Younis J, Moustafa H and Hussein M. Comparison Between In vivo Gates Method and in Vitro Plasma Sampling Method for GFR Measurement Using Tc-99m DTPA. Egyptian J Nucl Med 2014;10(20):33-45.

15. Ayan AK, Varoglu E, Keles M, Seven B,Uyanik A and Orsal E. 2016. Comparison of glomerular filtration rate measurements with the two-plasma sample technique using Tc-99m DTPA and other methods in donor candidates for renal transplantation. Turk J Med Sci 2016;46:1025-32.

16. Aydin F, Budak ES, Demirelli S, Oner AO, Korkmaz S and Suleymanlar $\mathrm{G}$ et al. Comparison of Cystatin $\mathrm{C}$ and $\beta$-Trace Protein Versus Tc-99m DTPA Plasma Sampling in Determining Glomerular Filtration Rate in Chronic Renal Disease. J Nucl Med Technol 2013; 43(30):206-13.

17. Itoh K. Comparison of methods for determination of glomerular filtration rate: Tc-99m-DTPA renography, predicted creatinine clearance method and plasma sample method. Ann Nucl Med 2003;17(7):561-5.

18. Jackson JH, Blue PW and Ghaed N. Glomerular filtration rate determined in conjunction with routine renal scanning. Radiology 1985;154(1):203-5.

19. Zuo L, Wang YC, Wang M, Zhang CL, Wang RF and Wang HY. Prediction of two-sample Tc-99m diethylenetriaminepentaacetic acid plasma clearance from single-sample method. Ann Nucl Med 2015;19:399-405. 